\title{
Hyperglycaemic Action of Lobelin and the Suprarenal Glands.
}

\author{
By \\ Masari Tiba. \\ (千 集 溯) \\ (From the Physiological Laboratory of Prof. I Satake, \\ Tohoku Imperial University, Sendai.)
}

According to previous writers, the hyperglycaemic action of lobelin is lost if the suprarenal capsules are excised or the splanchnic nerves interfered with.

The experimentalists ${ }^{122}$ who gave the drug soon after double decapsulation concluded so, but such an experimental condition can not be taken as satisfactory, as is, for example, emphasized by Randles ${ }^{3)}$ in the lobelin experiments.

Bertra mlinjected lobelin into rabbits in a subcutaneous dose of $5 \mathrm{mgrms}$. per kilo 3 hours after double decapsulation under ether. The rapidity with which the blood sugar concentration was falling under the normal level was not altered by lobelin. Tsuchi y $\mathrm{a}^{2)}$ experimented quite similarly with Bertra m, except that no narcosis was resorted to, and gave the drug earlier, i.e. 15-30 minutes after the decapsulation. The magnitude of hyperglycaemia in the rabbits poisoned with lobelin did not differ from that in the rabbits injected with the Ringer.

$R$ and le $\mathrm{s}^{3)}$ tried to intervene various length intervals of time between the double removal of the suprarenal bodies and the lobelin administration, and came to conclude that it is not safe to use rats under 3 weeks following suprarenalectomy.

While an intraperitoneal application of lobelin in doses of 22 to $44 \mathrm{mgrms}$. per kilo caused in normal rats an increase of blood sugar concentration by $66-$ $68 \%$, a markedly less degree of the increase was noted in the rats doubly suprarenalectomized, such as 10\% 3-7 days after decapsulation, 19\% 27-40 days

1) Bertram, Arch. f. exp. Path. u. Pharm., 1928, 28, 179.

2) Har a and T such i y a, Nippon Yakubutugaku Zassi, 1935, 20, Proc. 95; Jap. J. of med. Sci., Pharm., 1936, 9, 124 (Proe.); Tsu ch i y a, Zikken Yakubutugaku Zassi, 1937, 13, 234 ff; Nissin Igaku, 1937, 26, 629.

3) R a nd les, Am. J. of Physiol., 1931, 97, 553 (Proc.); J. of Pharm. \& Exp. Ther., 1931, 42, 272 (Proc.). 
and $3 \% 36-56$ days. Consequently he concluded that epinephrine is a factor, but not the only one, in lobelin hyperglycaemia.

In another set of experiments, i. e. with double splanchnicotomy, Tsu chiy a allowed 18 days or more to elapse after the nerve section till lobelin injection. There was also no increase or a very slight one in the blood sugar content on lobelin poisoning : from $0.113 \%$ to $0.122 \%$, from $0.120 \%$ to $0.124 \%$ and from $0.106 \%$ to $0.120 \%$.

On the other hand, that lobelin can induce an oversecretion of epinephrine from the suprarenal gland has been established, although there is a marked difference in respect to its scale of the augmentation between the report of Houssay and Molinelli $i^{4}$ and that of Inaba. ${ }^{5}$ ) The former reported further that a complete denervation of the suprarenal gland does not suppress the epinephrine liberation due to lobelin. This suggests some possible existence of causal relationship between the epinephrine oversecretion and the blood sugar increase in the case of lobelin.

Anitschkow $w^{6}$ and Kusnetzow ${ }^{7}$ saw that lobelin increases the epinephrine concentration of the fluid from the suprarenal gland of a cow or an ox, perfused with Ringer. $\mathrm{Hara}^{8)}$ detected a diminished load of epinephrine, determined by the Suto-In ou ye, in the rabbit suprarenal capsule on poisoning with lobelin.

The experiments which will be given in the following pages have been done under conditions not disturbing the carbohydrate metabolism by any factors other than the lobelin poisoning, and certain features from some previous have been yielded.

Methods: Healthy rabbits, fed on tofukara, carrot and straw, were experimented on. The splanchnic nerves were bilaterally cut beforehand. They were bilaterally interfered with either through the lumbar route in two sittings or per laparotomiam. The suprarenal glands were removed by the lumbar route in two sittings. No narcosis was resorted to in these operations. At least two weeks were allowed to elapse between the last operation and the lobelin injection.

The blood sugar content was estimated by the method of Fujita

4) Houssay and Molinelli, Rev. Soc. Arg. de Biol., 1925, 1 year, No. 5 (reprint); C. r. Soc. Biol., 1925, 93, 1124; Am. J. of Physiol., 1926, 76, 551; Molinelli, La secrecion de adrenalina, Buenos Aires 1926, $211 \mathrm{ff}$.

5) In a ba, Tohoku J. of Exp. Med., 1935, 27, 348.

6) Anitschkow, Arch. f. exp. Path. u. Pharm., 1928, 118, 242.

7) Kusnetzow, Ibid., 1928, 135, 333.

8) H a ra, Nissin Igaku, 1929-30, 19, 1903; Nippon Yakubutugaku Zassi, 1930, 10, Proc. 7; Jap. J. of Med. Sci., Pharm., 1931, 5, 11. H ar a and Ts u c hiya, Nissin Igaku,
1937, 26, 629. 
and Iwatake.9)

Alpha lobelin (Ingelheim) was injected as $1 \%$ solution intravenously (in 35-10 seconds and in a few instances in 2030 seconds) in doses of $3.5 \mathrm{mgrms}$. or 7 mgrms. per kilo of body weight, and subcutaneously (in 27 seconds) in doses of 5,10 or 20 mgrms. per kilo.

The blood sugar experiment was carried out without fastening and without narcotizing the animal. The heart rate, respiration frequen$c y$, and the rectal and room temperatures were measured from time to time.

\section{Results.}

As the control, some normal rabbits were also injected with lobelin.

Intravenous cases will be presented in the first place, and followed by the subcutaneous cases. All

9) Fujita and Iwatake, Biochem. Z., $1931,242,43$.

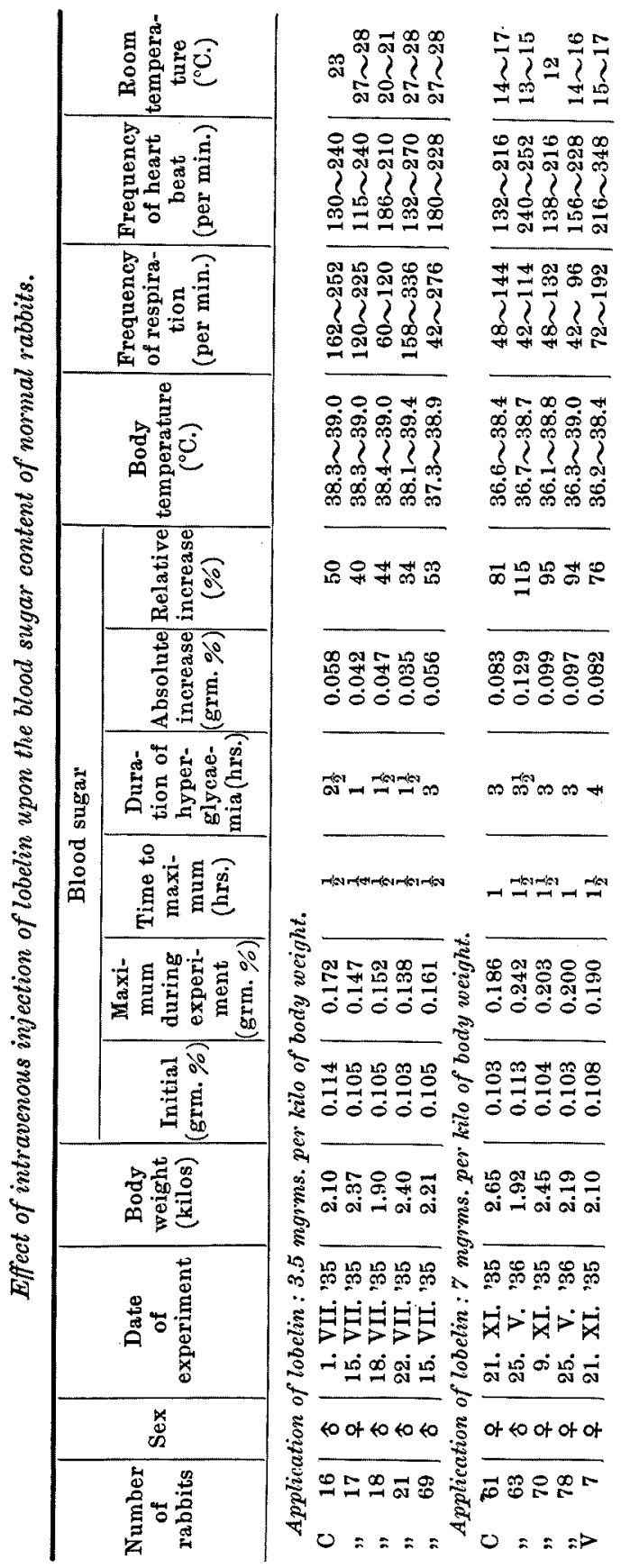


the data are epitomized in 6 tables.

\section{(A) Intravenous Injection. \\ (1) Normal rabbits (Tab. I).}

$3.5 \mathrm{mgrm}$. lobelin per kilo of body weight was the dose for $5 \mathrm{rab}$ bits, which showed hyperglycaemia of a moderate degree. $0.138-0.161$ grm. \% was the maximum reached at1/4-1/2 hour after the injection. (The blood samples were taken as a rule with intervals such as 5,15 , 30,60 minutes after the injection, and so on.) The hyperglycaemic spell continued for 1-3 hours.

A few minutes after the injection, miosis and convulsions occurred, the breathing became deep and slow for a while, then speeded up 15 minutes or so after the injection. 2 or 2.5 hours later the animal looked almost normal. The heart rate about 15 minutes after the injection, was measured having increased, and 11.5 hours later it resumed the initial value. The body temperature descended, with the bottom $37.3^{\circ}-38.4^{\circ} 15-12$ minutes, usually 30 minutes after the injection.

Double dose, i. e. $7 \mathrm{mgrms}$. lobelin was dosaged in another $5 \mathrm{rab}$ bits, resulting in severe clinical symptoms and profound and prolonged hyperglycaemia. $\quad 0.186-0.242 \mathrm{grm} . \%$ was the greatest blood sugar content, measured 1-1.5 hours after the injection, and the hyperglycaemic period covered over 3-4 hours.

At the end of observation extending for 3 hours after the injection, the blood sugar content showed in all the cases about the same value with the initial or else a lower. In a case with $3.5 \mathrm{mgrm}$. Iobelin(C) 18 it was $0.087 \%$, and in a case with 7 mgrms. (C 70) $0.09 \%$.

The decrease of respiratory frequency and of the anal temperature was also considerable. $42-72$ breathings per minute contrast $42-162$ breathings in the cases of $3.5 \mathrm{mgrms}$. per kilo, and $36.1^{\circ}-36.7^{\circ}$ in these experiments, $37.3^{\circ}-38.3^{\circ}$ in those experiments with the smaller dosage.

(2) Doubly splanchnicotomized rabbits (Tab. II).

16-246 days after double splanchnicotomy, lobelin experiment was carried out.

8 rabbits were dosaged with 3.5 mgrms. per kilo. In 6 cases the clinical symptoms were slight, and no noticeable hyperglycaemia was discovered; there was only a slight increase such as from $0.111 \mathrm{grm} . \%$ to $0.126 \%$, from $0.102 \%$ to $0.117 \%$,from $0.104 \%$ to $0.114 \%$, from 0.105 $\%$ to $0.117 \%$, from $0.089 \%$ to $0.106 \%$ and from $0.092 \%$ to $0.126 \% .10$ minutes to 1 hour were needed to see the highest level, and the hyperglycaemic period covered 15 minutes to 3 hours. 


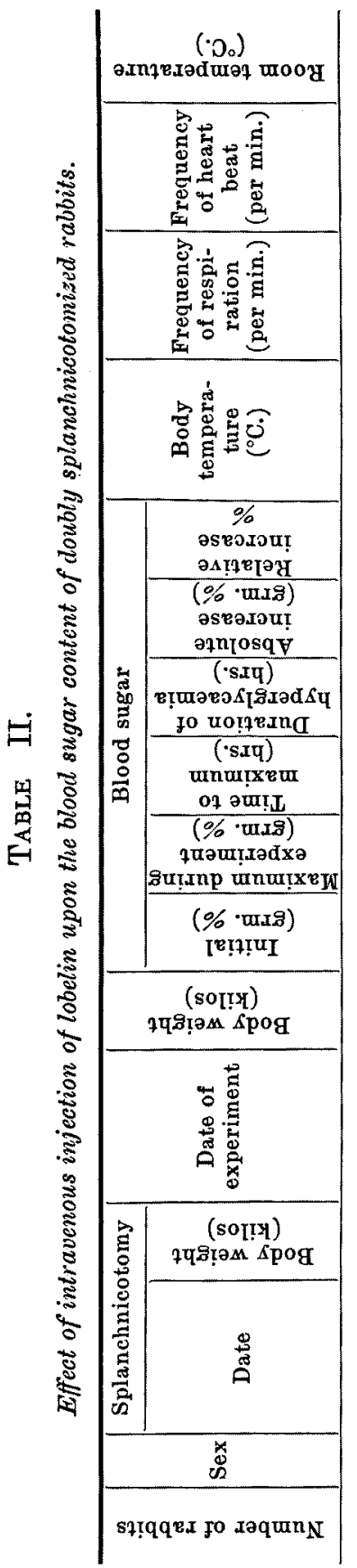

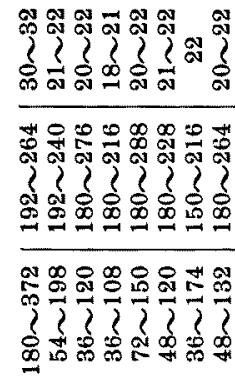

a N NON T T

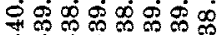
\}? ?? ?? ?

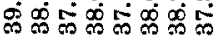

몽요요요요

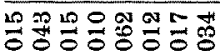
영ㅇㅇㅇㅇㅇㅇㅇㅇㅇ

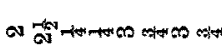

a

$-10 \sin 2000$

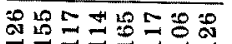

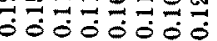

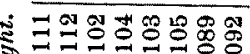
武

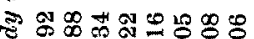

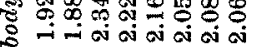
$<$ -

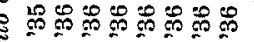

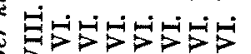

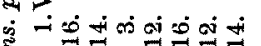
Sontomar

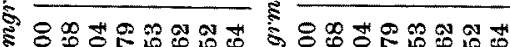

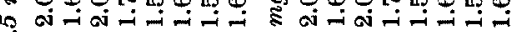

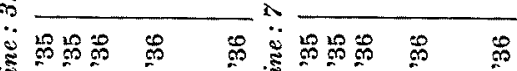

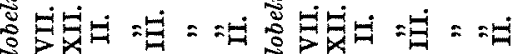
ல है of to to to to to of of of to to to to to of of

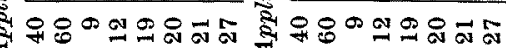

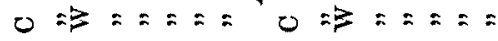


In two other cases (C60 \& W19) poisoning was severe, and correspondingly the blood sugar concentration increased largely, just as in normal rabbits, above given: from $0.112 \mathrm{grm} . \%$ to $0.155 \%$ and from $0.103 \%$ to $0.165 \%$, the maximum being noted respectively 15 minutes and 2 hours after the injection. The hyperglycaemic period covered about 3 hours.

In Rabbit $\mathrm{C} 60$, convulsions occurred soon on injecting lobelin, urination, miosis followed, conjunctiva cyanotic, respiration deep, and then slow (60 breathings per minute 3 minutes after the injection). 5 minutes after the injection dyspnoeic, the animal lay down, 27 minutes after the injection it stood up, mydriasis, deep \& slow respiration. Almost similar symptoms were noted in Rabbit W19; in this case convulsive seizures took place repeatedly.

The body temperature fell on a similar scale with the normal rabbits poisoned with the same dose of drug; in the two cases with a larger increase in the blood sugar content the body temperature fell similarly. The respiration became commonly slow.

7 mgrms. lobelin per kilo was capable of bringing about an evident hyperglycaemia in nearly all the cases, 8 in number, W12 being a single exception where the blood sugar remained almost unchanged (from $0.110 \%$ to $0.115 \%$ ). In 7 cases the maximum was $0.136 \mathrm{grm}$. $\%-0.174 \%$, definitely smaller than in normal rabbits poisoned with the same amount of lobelin $(0.186 \%-0.242 \%)$. 45-60 minutes elapsed till the maximum was reached, the hyperglycaemic period covered 2-4 hours.

In the doubly splanchnicotomized rabbits the blood sugar content was often estimated having gone down in the later stage of poisoning. In Rabbit W9 $0.092 \% 2$ hours after the injection of $3.5 \mathrm{mgrms}$. per kilo, in Rabbit W12 0.093\% 1.5 hours and in Rabbit W21 $0.096 \% 2.5$ hours, and in Rabbit W27 $0.075 \% 3$ hours; in the series of $7 \mathrm{mgrms}$. per kilo, $0.088 \% 3$ hours in Rabbit C 60, 0.079\% 4 hours in Rabbit W9, $0.093 \% 3.5$ hours in Rabbit W20, $0.076 \% 4$ hours in Rabbit W21, and $0.097 \% 4$ hours in Rabbit W29. There were thus some strong tendencies of hypoglycaemia developing in the doubly splanchnicotomized rabbits, especially when heavily poisoned.

Clinical symptoms were severe in general, but if examined case by case, they were rather moderate in some animals $(\mathrm{C} 40, \mathrm{C} 60, \mathrm{~W} 12, \mathrm{~W} 27)$. The body temperature fall corresponded to the amount of drug, and was about the same with that of the normal rabbits poisoned with the same dosage. Respiration became invariably slow.

Double splanchnicotomy inhibits to some extent a full development of the lobelin hyperglycaemia; this does not check well with the 
report of Tsuchiya, who was able to see a rather complete disappearance of lobelin hyperglycaemia in the rabbits surviving the same operation over 18 days. In the present experiments, lobelin was administered 76188 days after the denervation.

(3) Doubly suprarenaleetomized rabbits (Tab. III).

In 6 rabbits, 97-265 days after double suprarenalectomy lobelin was administered in the dose of 3.5 mgrms. per kilo. The blood sugar concentration increased in all the cases, but only in-

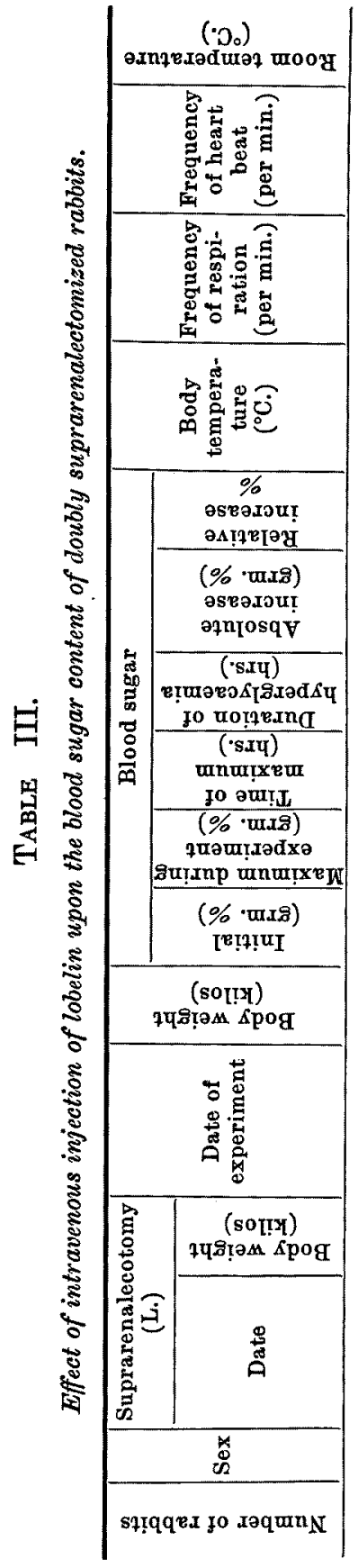

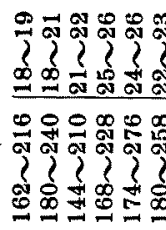

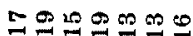

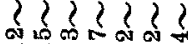
-

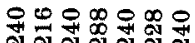
)

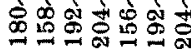

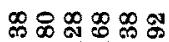
रे?

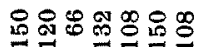

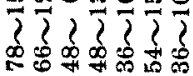

is $0-\pi$ as $\infty \infty$ क⿺ ? ? ? ? ? ? भु?

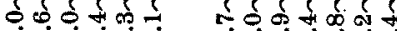

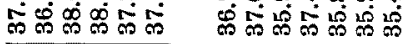

○ N

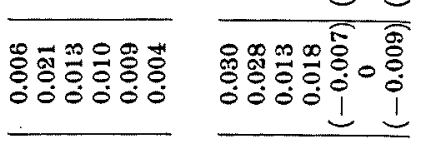

-

$\longrightarrow$

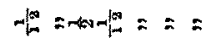

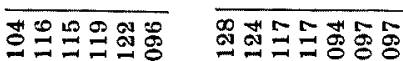

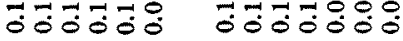

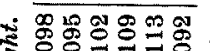

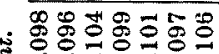

s. $00000 \%$ 0ं0் $0 \dot{0} \dot{0}$

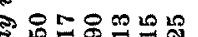

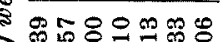

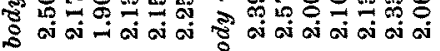

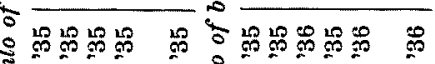

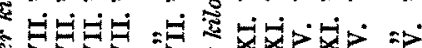

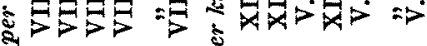
ช 9. \% $188 \%$ \%

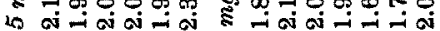
के

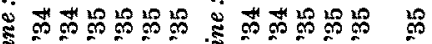

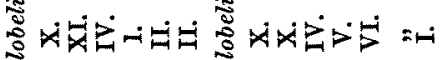

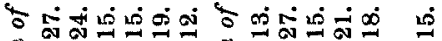
of to to of to to है of of to to to to ot

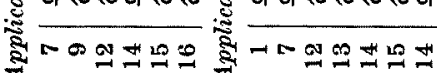
श 
significantly, $0.096 \mathrm{grm} . \%-0.122 \%$ being the highest against $0.092 \%-$ $0.113 \%$ of the initial. The hyperglycaemic period covered only a short interval, 1 hour being the longest.

$7 \mathrm{mgrms}$. lobelin per kilo were also incapable of causing an evident increase in the blood sugar level in the doubly suprarenalectomized rabbits as in the smaller dosage. The intravenous injection was carried out 183 -499 days after the decapsulation. In 4 cases out of 7 a small hyperglycaemia, such as from $0.098 \mathrm{grm}$. \% to $0.128 \%$, from $0.096 \%$ to $0.124 \%$, from $0.104 \%$ to $0.117 \%$ and from $0.099 \%$ to $0.117 \%$, developed, the time when the highest value was measured and the time course of the hyperglycaemia were similar with the cases of the small dosage. In the remaining 3 cases there was no increase, but only a small decrease.

In the decapsulated animals hypoglycaemia was detectable in most of the cases, only this tendency was doubtful in No. X 15; the smallest concentration was in some cases under $0.07 \%$ and over $0.05 \%$ (3.5 mgrms: C 9, X 16; 7 mgrms.: C 14, X 14).

Among 3.5 mgrms. series, in Rabbits C 12 \& X 15 clinical symptoms were slight, in Rabbit X 14 no convulsive attacks took place, but the animal excited for a while; among the cases heavily dosaged, severe symptoms were noted in $\mathrm{C} 12$ and $\mathrm{C} 15$.

The body temperature fall was of almost the same degree as the normal rabbits, only in 3 rabbits (C 14, C $15 \& \mathrm{X} 14$ ) which showed no increase in the blood sugar concentration at all, the body temperature fell more so; at that moment the blood sugar content was already diminishing.

Of the respiratory frequency there was no material difference compared with the other series of experiments.

The removal of the suprarenal capsules thus abolishes very largely the hyperglycaemic response of the rabbit against lobelin. This checks well with the conclusion of the previous observers ${ }^{122}$, who gave the drug soon or a few hours after the decapsulation per laparotomiam. And apparently this corresponds to the findings of Hous s a y and Molinelli that the denervation of the suprarenal capsule does not prevent oversecretion of epinephrine due to lobelin.

(B) Hypodermical Injection.

In some groups of rabbits lobelin was injected subcutaneously in doses of 5 mgrms., $10 \mathrm{mgrms}$. and 20 mgrms.

\section{(1) Normal rabbits (Tab. IV).}

5 mgrms. lobelin per kilo did not produce convulsions in 3 rabbits, 


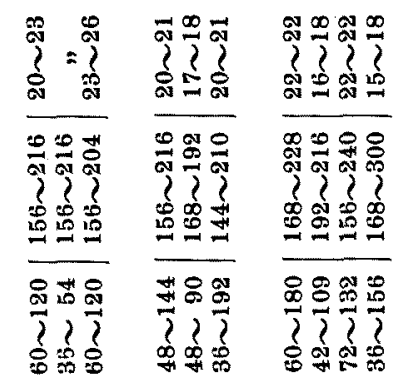

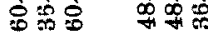

000

웅ํำ

?? ??

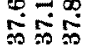

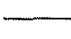

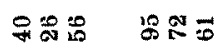

$\bar{x}$

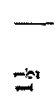

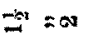

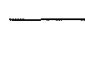

$\min =\operatorname{sit}$

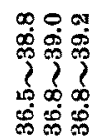

$\operatorname{8กำ~}$

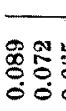

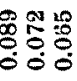

$4=$

$+2=\infty$

$\infty 00$

象离通品

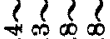

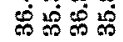

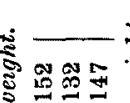

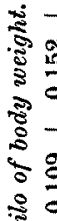

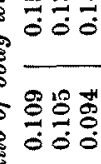

온

है

हैं -

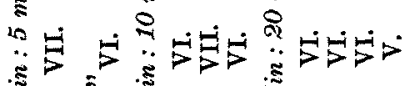

芯 =

-

아 하알

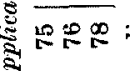

- से

to of of 돌 to to of of

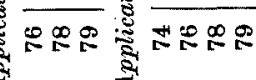

but miosis, and deep and slow respiration appeared, and the animals lay down on their side and finally mydriasis took place 1 or 1.5 hours after the injection.

10 mgrms. lobelin per kilo was enough to cause convulsive seizures ; usually 1 hour was needed before the animal with mydriasis could get up. Clinical symptoms were slight in Rabbit C 78.

With 20 mgrms. lobelin per kilo, the animals, 4 in number, looked more heavily intoxicated, but in Rabbit $\mathrm{C}$ 76 the poisoning was not heavy, judging from clinical symptoms, and correspondingly the hyperglycaemia was of a somewhat lesser degree. In Rabbit $\mathrm{C} 79$ the poisoning symptoms 

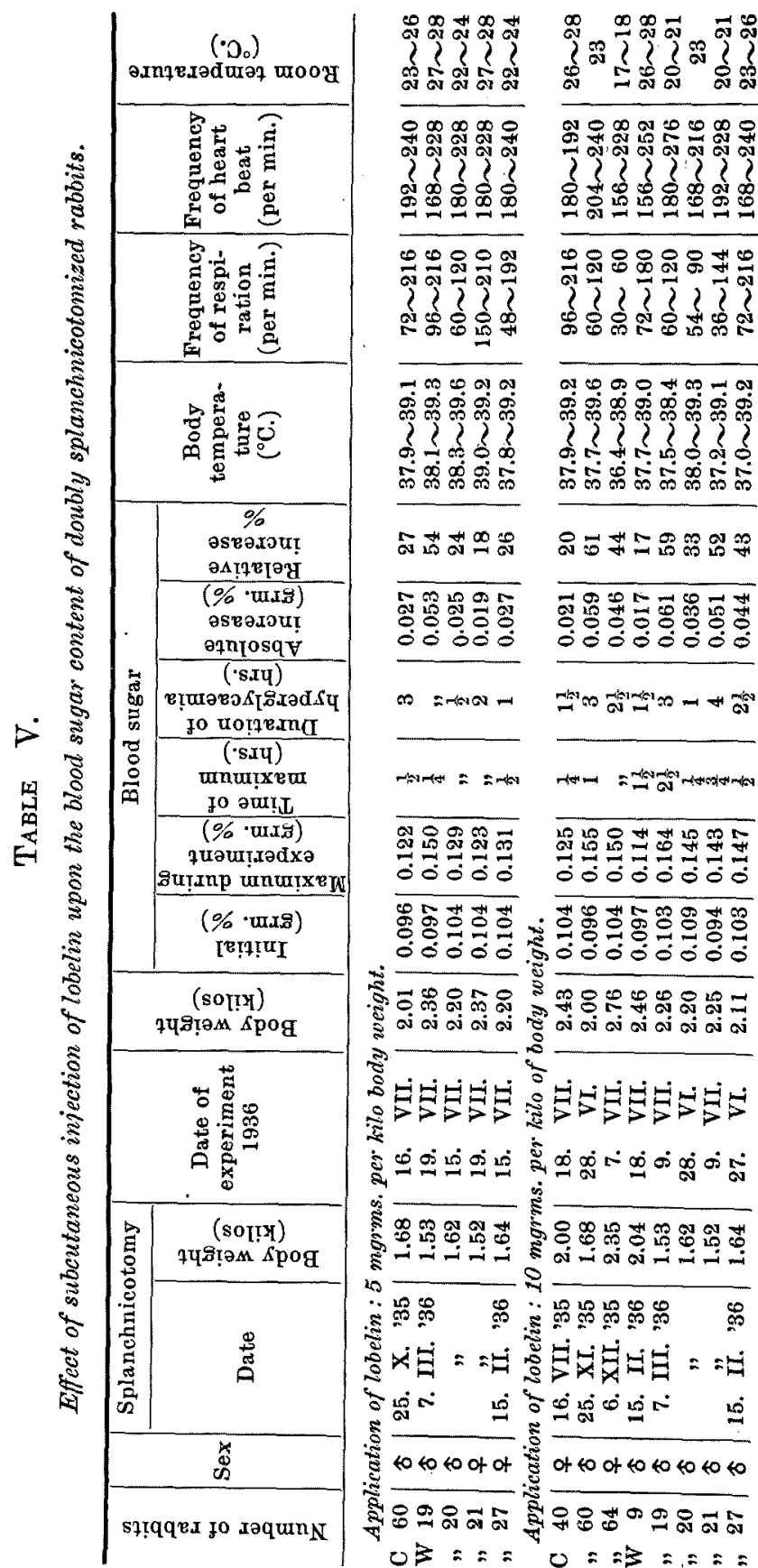

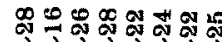
ใद ? ? ? ? ? -

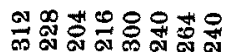
\{\}? ? ? ? ?

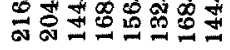

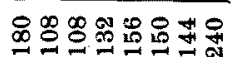
रे?

- 50 o o 0

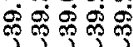
रใ\}?

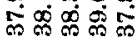

$000 \% 0 \div 0$

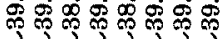

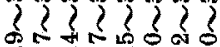

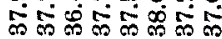

m $09 \div-\infty \div-1$ 郘品品品品品 \{द? ? ? ? ?

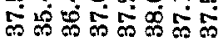

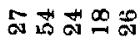

뒁영영형

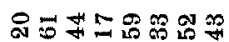

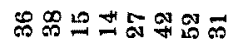

00000

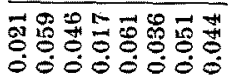

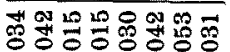
$\circ 000000$ o 0.000000

$m=$ mon $n$

$\Rightarrow$ का

$\infty \cos ^{\infty} \rightarrow+\infty$

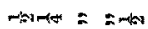

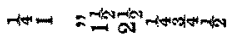

a)

옹영

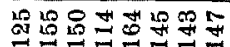

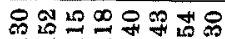
영ㅇㅇ 영 형ㅎㅇ 형ㅎㅎㅎㅇㅇㅎㅇㅇㅎㅇ 员或苍句苍

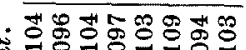

융용요형하 ó丶0்

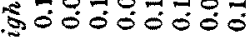
훙요웅

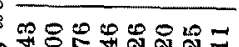
ó 0 ó ov ai a ai ai

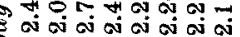

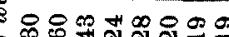

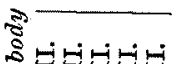

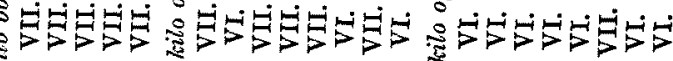
ڤஸ்

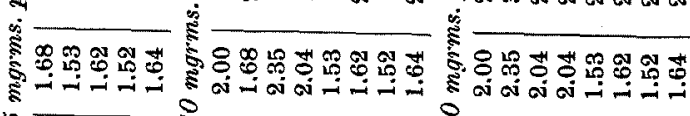
is

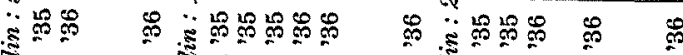

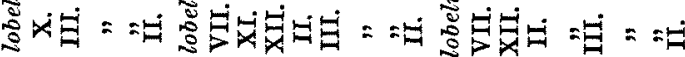
ठิ

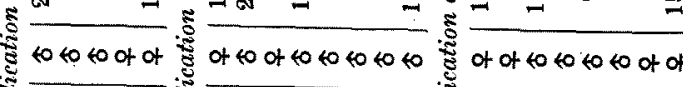

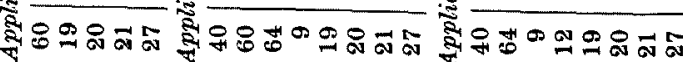

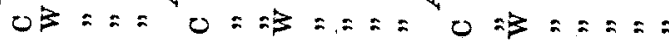


were not so heavy and the blood sugar concentration was also correspondingly not so large.

In all the cases the blood sugar concentration increased, and just in correspondence to the amount of lobelin, $0.15 \%$ for $5 \mathrm{mgrms} ., 0.18 \%$ for $10 \mathrm{mgrms}$. and $0.2 \%$ for $20 \mathrm{mgrms}$. and the interval of time elapsed to the maximum concentration also corresponded to those values. The hyperglycaemic spell was 1.5-2hours in the cases of the smallest dosage, and 3-4 hours in the cases with heavier dosages.

The body temperature fell by 2 degrees in the cases with 5 mgrms. per kilo, and by $3^{\circ}$ or more in those with $10 \mathrm{mgrms}$. and $20 \mathrm{mgrms}$. Of the slow respiration there was no material difference between the various dosages.

Of the blood sugar events subcutaenous $5 \mathrm{mgrms}$. per kilo corresponds to intravenous 3.5 mgrms., but the clinical symptoms lasted much longer in the former, and they seemed somewhat heavier. Subcutaneous 20 mgrms. per kilo caused hyperglycaemia of almost the same degree as intravenous $7 \mathrm{mgrms}$. per kilo; clinically the poisoning lasted much longer in the former, as is to be anticipated.

\section{(2) Doubly splanchnicotomized rabbit (Tab. V).}

In these rabbits, long surviving double splanchnicotomy(111-368 days), subcutaneous application of lobelin caused some rise in the blood sugar concentration. 5 mgrms. lobelin per kilo induced $0.122-0.150$ grm. \% blood sugar in 5 rabbits, mean $0.13 \%$, a little smaller degree of hyperglycaemia in comparison to the normal animals. $10 \mathrm{mgrms}$. per kilo $0.14 \%(0.114-0.164 \%)$ in 8 rabbits and 20 mgrms. per kilo $0.13 \%$ in 8 others.

In this set of experiments, that is the doubly splanchnicotomized rabbits with subcutaneous application of lobelin, the blood sugar variation during the lobelin intoxication was not simple, contrary to the other sets.

As Example III shows, (Here are three examples displayed from normal animals, doubly splanchnicotomized and doubly suprarenalectomized, in order to show general experimental routine and symptoms.) the blood sugar content started to increase soon on the injection, and it did not decrease with the elapse of time, but it was apt again to increase, so that there are two acmes in the hyperglycaemic curves. In the case quoted here, Rabbit W19, there were some convulsive attacks before and during the second increase of blood sugar. In the other examples the second summit was not preceded or accompanied by convulsive seizures or anyting of that nature (10 mgrms: C40, W21, 20 mgrms.: C 


\section{EXAMple I.}

Normal rabbit No. C 79. 우 2.28 kilos. 28. V. '36.

\begin{tabular}{|c|c|c|c|c|c|c|c|c|}
\hline \multirow{2}{*}{\multicolumn{2}{|c|}{$\begin{array}{l}\text { Time before } \\
\text { or after } \\
\text { injection } \\
\text { (min.) }\end{array}$}} & \multirow{2}{*}{ 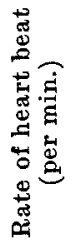 } & \multirow{2}{*}{ 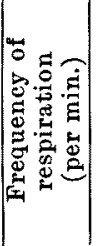 } & \multirow{2}{*}{ 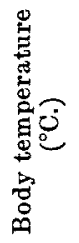 } & \multirow{2}{*}{ 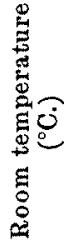 } & \multicolumn{2}{|c|}{$\begin{array}{l}\text { Blood sugar } \\
\text { content }\end{array}$} & \multirow[b]{2}{*}{ Remarks } \\
\hline & & & & & & 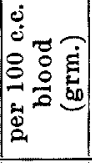 & Rate & \\
\hline before & 20 & 180 & 48 & 38.7 & 15 & 0.101 & 95 & 8.1. '36 (1.68 kilos) cut auri- \\
\hline$"$ & 10 & 168 & 42 & 38.7 & 15 & 0.106 & 100 & cular nerves on both sides. \\
\hline \multicolumn{8}{|c|}{$\begin{array}{l}9: 50 \text { a.m. } 4.5 \text { c.e. } 1 \% \text { lobelin ( } 20 \text { mgrms. per kilo) } \\
\text { subcutaneously injected in } 7 \text { seconds. }\end{array}$} & $\begin{array}{l}3 \text { minutes after the injection } \\
\text { violent convulsions, miosis, }\end{array}$ \\
\hline after & 15 & 300 & 156 & 37.5 & 16 & $0.144 \mid$ & 136 & respiration deep \& slow, then \\
\hline & 30 & 240 & 132 & 36.7 & 16 & 0.162 & 153 & lay down on its side. 5 minutes \\
\hline & 45 & 192 & 132 & 36.0 & 16 & 0.176 & 166 & after injection Respiration be \\
\hline & 60 & 168 & 54 & 35.8 & 16 & 0.194 & 183 & came frequent, shallow 120 per \\
\hline$"$ & 90 & 180 & 48 & 36.3 & 17 & 0.198 & 187 & min.). 10 minutes after injec- \\
\hline " & 120 & 180 & 54 & 37.1 & 17 & 0.174 & 164 & tion convulsions, respiration \\
\hline & 150 & 180 & 48 & 37.8 & 17 & 0.136 & 128 & frequent and shallow as before. \\
\hline 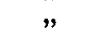 & 180 & 180 & 36 & 38.1 & 17 & 0.118 & 112 & 15 minutes after injection $\mathrm{my}$ \\
\hline " & 210 & 180 & 48 & 38.1 & 18 & 0.110 & 104 & driasis, and got up, but not set \\
\hline & 240 & 180 & 48 & 38.5 & 18 & 0.101 & 95 & completely recovered. \\
\hline
\end{tabular}

40, W9, W12, W20, W21, W27). The time when the summits appeared was $15 \mathrm{~min}$. \& $150 \mathrm{~min}$. in W19, $45 \mathrm{~min}$. \& $180 \mathrm{~min}$. in W21, 15 min. \& $120 \mathrm{~min}$. in W12, $15 \mathrm{~min}$. \& $180 \mathrm{~min}$. in W19, $45 \mathrm{~min}$. \& $150 \mathrm{~min}$. in W20, $15 \mathrm{~min}$. \& $90 \mathrm{~min}$. in W21, and $30 \mathrm{~min}$. \& $150 \mathrm{~min}$. in W29.)

The blood sugar curve without two summits was rare in the doubly splanchnicotomized rabbits poisoned bysubcutaneous injection of greater doses of lobelin such as 20 mgrms. per kilo. In the experiments with 10 mgrms. per kilo, the curve with two summits was rather infrequently met with (W19, W21 among 8 cases).

Such a fluctuation, showing two summits, was seldom observable in some cases of the other series of experiments, that is in the doubly suprarenalectomized cases: 7 mgrms. i. v. C7, C12, C13, C15; 5 mgrms. subc. C 1, 10 mgrms. C 1, 20 mgrms. C 7. Although the scale of the fluctuations was small in these suprarenalectomized animals, it must be taken as definitely having established that there are some processes in the carbohydrate metabolism in the organism poisoned with lobelin to bring about two summits in the blood sugar curve, provided the splanchnic nerves or the suprarenal capsules are ruled out. This occurred more frequently when the drug was given in a large amount, such as 7 mgrms. per kilo intravenously or 20 mgrms. per kilo subcutaneously. 
ExAMPLE II.

Doubly splanchnicotomized rabbit No. W 19. ô 2.26 kilos. 9. VII. '36.

\begin{tabular}{|c|c|c|c|c|c|c|c|c|}
\hline \multirow{2}{*}{\multicolumn{2}{|c|}{$\begin{array}{l}\text { Time before } \\
\text { or after } \\
\text { injection } \\
\text { (min.) }\end{array}$}} & \multirow{2}{*}{ 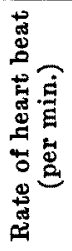 } & \multirow{2}{*}{ 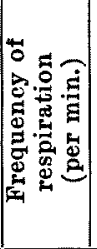 } & \multirow{2}{*}{ 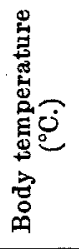 } & \multirow{2}{*}{ 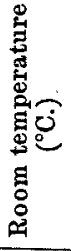 } & \multicolumn{2}{|c|}{$\begin{array}{c}\text { Blood sugar } \\
\text { content }\end{array}$} & \multirow[b]{2}{*}{ Remarks } \\
\hline & & & & & & 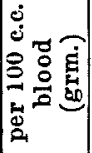 & Rate & \\
\hline before & 20 & 204 & 96 & 38.4 & 20 & 0.096 & 93 & 29. II. '36 (1.59 kilos) r. sp- \\
\hline$"$ & 10 & 192 & 114 & 38.4 & 20 & 0.103 & 100 & $\begin{array}{l}\text { lanchnicotomy, 7. III ' } 36 \text { (1.53 } \\
\text { kilos) 1. splanchnicotomy and } \\
\text { cut auricular nerves on both } \\
\text { sides. }\end{array}$ \\
\hline \multicolumn{8}{|c|}{$\begin{array}{l}9: 50 \text { a.m. } 2.3 \text { c.c. } 1 \% \text { lobelin (10 mgrms. per kilo) } \\
\text { subcutaneously injected in } 3 \text { seconds. }\end{array}$} & $\begin{array}{l}2 \text { minutes atter injection } \\
\text { miosis, respiration deep } \& \\
\text { slow, } 2 \text { minutes later slight }\end{array}$ \\
\hline after & 15 & 228 & $96 \mid$ & 37.9 & 20 & $0.143 \mid$ & 139 & convulsions for 3 seconds, 5 \\
\hline$"$ & 30 & 240 & 120 & 37.7 & 21 & 0.107 & 104 & minutes further later slight \\
\hline$"$ & $\mathbf{4 5}$ & 228 & 90 & 37.5 & 21 & 0.096 & 93 & convulsions, then sprang out \\
\hline 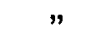 & 60 & 276 & 96 & 37.6 & 21 & 0.101 & 98 & of the basin, convulsions, lay \\
\hline$"$ & 90 & 240 & 120 & 37.5 & 21 & 0.112 & 108 & down, dyspnoeic, 15 minutes \\
\hline$"$ & 120 & 228 & 96 & 37.5 & 21 & 0.156 & 152 & after injection the animal get \\
\hline 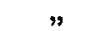 & 150 & 228 & 84 & 37.7 & 21 & 0.164 & 159 & up, but was attacked several \\
\hline 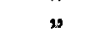 & 180 & 180 & 72 & 38.1 & 21 & 0.105 & 102 & times by convulsions and roll- \\
\hline " & 210 & 180 & 60 & 38.1 & 21 & 0.096 & 93 & ed over. 90 minutes and 130 \\
\hline$"$ & 240 & 228 & 96 & 38.2 & 21 & 0.096 & 93 & $\begin{array}{l}\text { minutes after injection con- } \\
\text { vulsive seizures. } 3 \text { hours after } \\
\text { injection the animal looked } \\
\text { nearly normal. }\end{array}$ \\
\hline
\end{tabular}

Some co-relation can be considered of both facts that the large dose, i.e. 20 mgrms. per kilo, was capable of eliciting only a rather small degree of hyperglycaemia, that is smaller than $10 \mathrm{mgrms}$. and almost the same as $5 \mathrm{mgrms}$, and there were usually fluctuations presenting two summits in those cases.

The time when the highest content was reached was short in the cases with 5 mgrms. lobelin per kilo; it was variable in the cases with 10 and 20 mgrms., and there was rather commonly a tendency that this time interval was longer, when the maximum value was larger. Clinical symtoms in the cases of 5 mgrms. per kilo were of similar intensities with the normal rabbits; only in Rabbit W 21 convulsions occurred, and all the rabbits got up 1-1.5 hours after the injection, when mydriasis was persisting.

Among 8 doubly splanchnicotomized rabbits which received, under the skin, lobelin in a dose of $10 \mathrm{mgrms}$. per kilo, one (W 19) suffered seriously from poisoning, convulsions occurred repeatedly, and 3 hours were needed for recovery, hyperglycaemia was the largest in this case $(0.164 \%)$; in other cases the animals got up about 1 hour after the injection, some rabbits earlier, some later. In a few cases mydriasis did not occur. No convulsions took place in Rabbit $\mathrm{C} 60$, in which hyperglycaemia was of a great degree $(0.155 \%)$. 
ExAMPLE III.

Doubly suprarenalectomized rabbit No. C 12. o 2.0 kilos. 27. V. '36.

\begin{tabular}{|c|c|c|c|c|c|c|c|c|}
\hline \multirow{2}{*}{\multicolumn{2}{|c|}{$\begin{array}{l}\text { Time before } \\
\text { or after } \\
\text { injection } \\
\text { (min.) }\end{array}$}} & \multirow{2}{*}{ 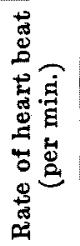 } & \multirow{2}{*}{ 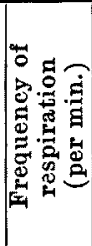 } & \multirow{2}{*}{ 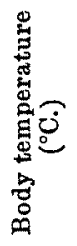 } & \multirow{2}{*}{ 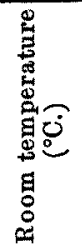 } & \multicolumn{2}{|c|}{$\begin{array}{c}\text { Blood sugar } \\
\text { content }\end{array}$} & \multirow[b]{2}{*}{ Remarks } \\
\hline & & & & & & 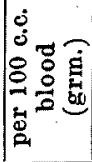 & Rate & \\
\hline $\begin{array}{c}\text { before } \\
"\end{array}$ & $\begin{array}{l}20 \\
10\end{array}$ & $\begin{array}{l}180 \\
192\end{array}$ & $\begin{array}{l}60 \\
66\end{array}$ & $\begin{array}{l}38.4 \\
38.5\end{array}$ & $\begin{array}{l}13 \\
13\end{array}$ & $\begin{array}{l}0.104 \\
0.104\end{array}$ & $\begin{array}{l}100 \\
100\end{array}$ & $\begin{array}{l}\text { 3. X. '34 (1.75 kilos) r. supra- } \\
\text { renalectomy (132 mgrms.), } 15 . \\
\text { IV. ' } 35(2.0 \text { kilos) l. suprarena- } \\
\text { lectomy ( } 950 \text { mgrms. }) \text { and cut } \\
\text { auricular nerves on both sides. }\end{array}$ \\
\hline
\end{tabular}

$9: 40$ a.m. 1.4 c.c. $1 \%$ lobelin ( 7 mgrms. per kilo) intravenously injected in 4 seconds.

\begin{tabular}{|c|c|c|c|c|c|c|c|c|}
\hline \multicolumn{8}{|c|}{ intravenously injected in 4 seconds. } & \multirow{2}{*}{$\begin{array}{l}45 \text { seconds after the injec- } \\
\text { tion lay down on its side, con- }\end{array}$} \\
\hline after & 5 & 228 & 60 & 一 & - & 0.112 & 107 & \\
\hline not & 10 & 228 & 90 & . & - & 0.106 & 102 & vulsions, miosis, conjunctivae \\
\hline " & 15 & 228 & 96 & 36.5 & 13 & 0.110 & 106 & cyanotic. Respiration deep \& \\
\hline$"$ & 30 & 216 & 96 & 35.6 & 14 & 0.117 & 112 & slow. 3 minutes after injection \\
\hline 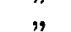 & 45 & 216 & 66 & 35.5 & 14 & 0.115 & 110 & respiration 36 per min.. \\
\hline " & 60 & 228 & 54 & 35.6 & 14 & 0.115 & 110 & 4 minutes after injection \\
\hline " & 90 & 216 & $\mathbf{6 6}$ & 35.9 & 14 & 0.101 & 97 & convalsions began to occur a- \\
\hline$"$ & 120 & 222 & 60 & 36.5 & 14 & 0.090 & 86 & gain, and up to 12 minutes \\
\hline , & 150 & 228 & 48 & 36.7. & 14 & 0.082 & 79 & several times. Somewhat dy- \\
\hline. & 180 & 240 & 48 & 37.0 & 14 & 0.082 & 79 & spnoic. 30 minutes after in- \\
\hline , & 210 & 240 & 48 & 37.6 & 14 & 0.083 & 80 & jection mydriasis, and got up, \\
\hline , & 240 & 216 & 48 & 37.8 & 14 & 0.087 & 83 & respiration almost normal. \\
\hline
\end{tabular}

In general the big dose of lobelin (i.e. $20 \mathrm{mgrms}$. per kilo) produced heavy, prolonged symptoms, only in Rabbits C 64 (0.152\%), W $12(0.118 \%)$, W $21(0.154$ $\%$ ), especially in Rabbit W 9 (0.115\%) symptoms were somewhat slight and continued not long.

The body temperature fell invariably in all cases, the larger the dose, the larger the fall, but this time the fall was in general of relatively small degree and there were only small differences in the magnitude of the temperature fall between the doses, the average lowest body temperature being $38.2^{\circ}$ for $5 \mathrm{mgrms}$. lobelin per kilo, $37.4^{\circ}$ for $10 \mathrm{mgrms}$., and $37.1^{\circ}$ for $20 \mathrm{mgrms}$., while they were respectively $37.5^{\circ}, 36.7^{\circ}$ and $36.0^{\circ}$ in the normal rabbits and further $37.2^{\circ}, 36.3^{\circ}$ and $34.6^{\circ}$ in the doubly suprarenalectomized ones, the data of which will be quoted below. This peculiarity in these doubly splanchnicotomized rabbits is not effected by the loss of the impulses by the way of these nerves, as the cases of the intravenous application gave no corroborating evidences, the figures being $38.1^{\circ}$ on $3.5 \mathrm{mgrms}$. per kilo and $36.4^{\circ}$ on $7 \mathrm{mgrms}$. in the normal rabbits, $38.1^{\circ}$ and $36.7^{\circ}$ in the doubly splanchnicotomized ones and $37.4^{\circ}$ and $36.2^{\circ}$ in the doubly suprarenalectomized.

These relatively small falls of the body temperature can be explained by the comparatively high room temperature, compared with the other groups of experiments; and this can be testified by the comparing the figures in cases quoted in Table V, for example. Among 8 cases with $10 \mathrm{mgrms}$. lobelin per kilo, the 
room temperature in the case of Rabbit $\mathrm{C} 64$ was lower $\left(17^{\circ}-18^{\circ}\right)$ than in the other cases, and the body temperature of that rabbit fell to $36.4^{\circ}$, the lowest in that group of experiments, and the experiment of $\mathrm{C} 64$ with $20 \mathrm{mgrms}$. Iobelin per kilo was carried out at the room temperature of $14^{\circ}-16^{\circ}$, and its body temperature fell to $35.4^{\circ}$, the lowest level among 8 rabbits poisoned with 20 mgrms. per kilo.

Respiratory frequency diminished in the doubly splanchnicotomized rabbits too.

\section{(3) Doubly suprarenalectomized rabbits (Tab. VI).}

319-639 days after the double suprarenalectomy, lobelin was given hypodermically. In these cases the blood sugar content increased only insignificantly in some cases or did not increase at all in other cases. When the increase occurred, it reached its maximum 15 minutes after the injection, that is at the blood sample first collected after the injection, and the hyperglycaemic period was correspondingly short also. It is only in the realm of remote possibility that some relationship exists between the doses and the magnitude of hyperglycaemia.

In these suprarenalectomized animals, hypoglycaemia was sometimes noted (5 mgrms.: W25, 10 mgrms.; C1, C15, W25, 20 mgrms. $\mathrm{C} 1, \mathrm{C} 7, \mathrm{C} 15, \mathrm{H} 9, \& \mathrm{~W} 25)$; the more the dose, the more frequent and the more profound it was. The minimum noted was $0.044 \%$ in $\mathrm{W} 25$ with 20 mgrms. per kilo, but this was of the sample collected 4 hours after the injection, i.e. the last sample, so that it remains unrecorded whether or not it was the lowest in that rabbit during the poisoning. All the experiments in the present investigations were extended for 3 or 4 hours after the injection; when the dose was smaller and the hypoglycaemia was accordingly of smaller magnitude, consequently there was always measured already some recovery in the blood sugar value in the elapse of 3 or 4 hours.

Among 4 cases of 5 mgrms. lobelin per kilo some severe symptoms were observed in a case (W25), where convulsive attacks and dyspnoeic respiration were noted, and 3 hours were not sufficient to see a complete recovery. In 3 other cases no convulsions took place, and one hour was sufficient to see a complete recovery. In Rabbit W29 with severe symptoms no increase was ever detected, while in the remaining cases there was trace of hyperglycaemia though very insignificant.

$10 \mathrm{mgrms}$. lobelin per kilo brought about rather slight intoxication symptoms in two rabbits without the suprarenals $(\mathrm{C} 1, \mathrm{H} 9)$, and somewhat stronger ones in the remaining 3 instances.

20 mgrms. lobelin per kilo were capable of causing severe, prolonged symptoms, only in Rabbit W25 miosis was slight and of a short interval and no con- 
vulsions took place, but there was a large fall in the body temperature and a considerable decrease of the blood sugar level, such as from $0.09 \%$ to $0.04 \%$.

The anal temperature fall was of about the same degree as in the normal rabbits. It was especially large in the cases with $20 \mathrm{mgrms}$. per kilo, $34.6^{\circ}$ and $36.0^{\circ}$ being the average values for the doubly suprarenalectomized ones and the normal.

Lobelin, applied either intravenously or hypodermically, was thus capable of causing an increase in the blood sugar concentration in normal rabbits, which corresponds on the whole to the doses applied. Clinical symptoms, especially the body temperature fall also roughly corresponded to the doses, though some irregularities were observable in the former.

The double splanchnicotomy effected some reduction in the hyperglycamia causable by lobelin, but when larger doses were applied the reduction was of smaller scale. However, there were some tendencies of developing the hypoglycaemic phase. And there were commonly detectable two summits of hyperglycaemia, say one 15-30 minutes after the injection, the second 2-3 hours after the injection, when a greater subcutaneous dose, such as 20 mgrms. per kilo, was applied, and usually the hyperglycaemia caused by subcutaneous 20 mgrms. perkilo was of smaller height than by $10 \mathrm{mgrms}$. in the doubly splanchnicotomized rabbits. The hyperglycaemic curve with two summits rarely occurred in other cases even with denervated or decapsulated animals.

The double removal of the suprarenal capsules almost inhibits an appearance of the hyperglycaemia causable by lobelin, though not entirely. In the rabbits without suprarenals, hypoglycaemia took place frequently, and the more the dose, the more frequent and profound it was.

From the above data, the suprarenal capsules are definitely indispensable for bringing about the lobelin hyperglycaemia, which fact corresponds to the findings of Hous s y and Molinelli, viz: that lobelin acts to liberate the epinephrine by acting on the suprarenal glands.

On the other hand the double splanchnicotomy diminishes without doubt the lobelin hyperglycaemia to some extent. Does then the lobelin act to increase the blood sugar concentration through the central mechanism for the carbohydrate metabolism?

This can be answered in the affirmative if the figures in the doubly suprarenalectomized rabbits in the present investigations and in those of Hatan $0,{ }^{10}$, who carried out the puncture of Bernard, be compared

10) Hatan o, Tohoku. J. of Exp. Med., 1936, 29, 455. 

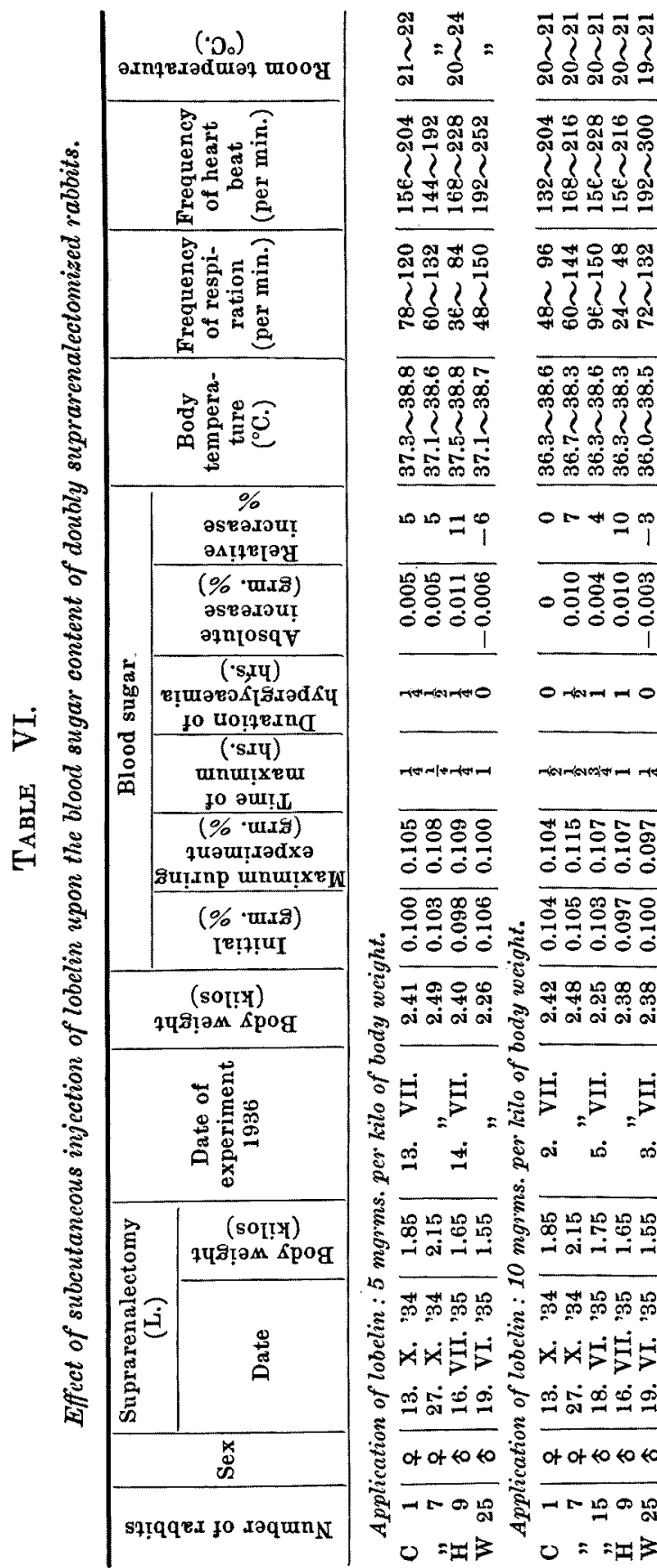

$\div \quad 20$

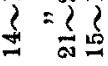

रे?

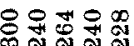

र???

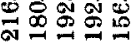

웅요용

रे?

$\infty 0 \infty$

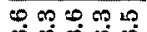

$\infty$

os ay $\begin{array}{ll}000 \\ 0\end{array}$

m

?? ??

? ? ? ?

冓唯

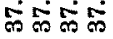

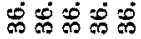

? 3 ?

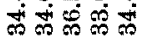

$\therefore D=0$

아요

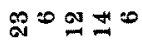

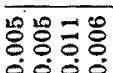

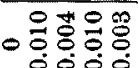

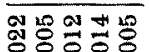

ร.
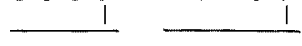

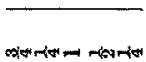

rimate

$0-1-0$

-1*-1

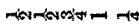

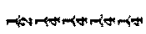

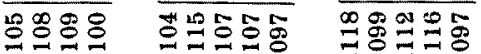

영응

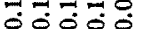

영영

$8 \%$

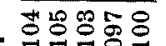

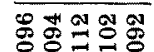

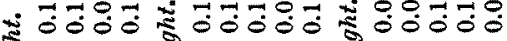

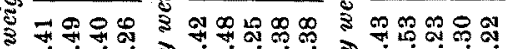
要

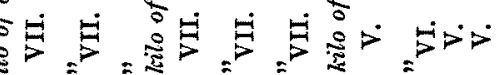

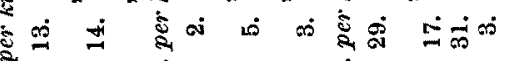
-

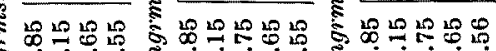

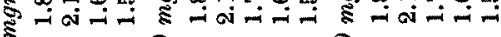

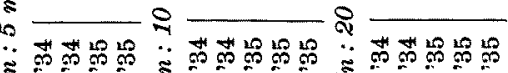

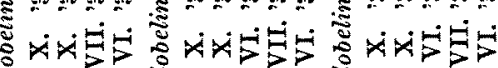

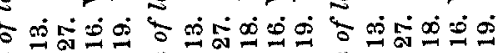

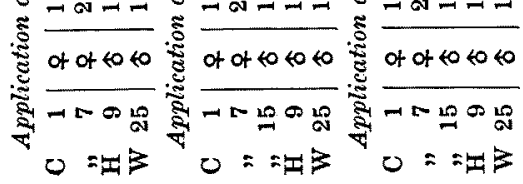


with each other.

As above discussed, the lobelin highly probably acts to increase the blood sugar concentration by acting on the suprarenal gIands, but there is still reason to take it as resulting by an oversecretion of epinephrine thereby; it is a question of the quantitative nature.

Some reduction in the lobelin hyperglycaemia in the doubly splanchnicotomized rabbits cannot be explained by the fact that that operation diminishes the glycogen storage, though small, ${ }^{11)}$ since it is without doubt that adrenaline can cause quite the same degree of hyperglycaemia in the rabbit so operated on as in the normal ones. ${ }^{\text {in }}$

\section{SUMMARY.}

Alpha lobelin was administered in rabbits, normal, doubly splanchnicotomized or doubly suprarenalectomized, intravenously (3.5 mgrms. or 7 mgrms. per kilo of body weight) or subcutaneously (5 mgrms., 10 mgrms., or 20 mgrms. per kilo). The latter two kinds of animals were indefinitely surviving and quite healthy.

Double splanchnicotomy diminishes the hyperglycaemia causable by lobelin to some extent, but if a large amount be given, lobelin is capable of causing some distinct increase in the blood sugar concentration. If subcutaneously heavily dosaged, there are rather commonly two summits in the hyperglycaemic curve and they are of smaller height.

Double suprarenalectomy is capable of causing the lobelin hyperglycaemia of an insignificant degree only, and if largely dosaged there develops frequently the hypoglycaemic stage.

From these facts it is deducible that the suprarenals are almost indispensable in causing the hyperglycaemia by lobelin, which act also to increase the blood sugar through the central mechanism for the carbohydrate metabolism, though not strongly so.

11) Morita, Ibid., 1921, 2, 423 \& 436, Mik a m i, Jap. J. of Med. Sci., Pharm., 1926. 1, 125-129; etc.

12) Tiba, Tohoku J. of Exp. Med., 1938, 32, 419. 